\title{
Orthorexia Nervosa and Executive Dysfunction: Symptomatology is Related to Difficulties with Behavioral Regulation
}

Natalie A. Noebel

Texas State University

Crystal D. Oberle ( $\square$ oberle@txstate.edu )

Texas State University https://orcid.org/0000-0002-6442-8706

Haley S. Marcell

Texas State University

\section{Research Article}

Keywords: Orthorexia nervosa, Executive function, Behavioral control, Emotional control

Posted Date: July 14th, 2021

DOl: https://doi.org/10.21203/rs.3.rs-704287/v1

License: (c) (i) This work is licensed under a Creative Commons Attribution 4.0 International License.

Read Full License

Version of Record: A version of this preprint was published at Eating and Weight Disorders - Studies on Anorexia, Bulimia and Obesity on January 8th, 2022. See the published version at https://doi.org/10.1007/s40519-021-01343-w. 
Orthorexia Nervosa and Executive Dysfunction:

Symptomatology is Related to Difficulties with Behavioral Regulation

Natalie A. Noebel, Crystal D. Oberle, \& Haley S. Marcell

Department of Psychology, Texas State University

Author Note

Affiliation and address of all authors: Department of Psychology, Texas State University, 601 University Dr., San Marcos, TX 78666, USA

Corresponding author: Crystal D. Oberle, oberle@txstate.edu, phone: 512-944-9577, ORCID: $\underline{0000-0002-6442-8706}$ 


\begin{abstract}
Purpose: This research explored whether orthorexia nervosa is associated with deficits in executive function.

Method: Participants $(n=405 ; 80 \%$ women, $53 \%$ White, mean age $=24$, mean body mass index = 25) completed the Orthorexia Nervosa Inventory (ONI) and the Behavior Rating Inventory of Executive Function-Adult version (BRIEF-A).

Results: ONI scores were significantly correlated with all BRIEF-A scales, exhibiting the strongest correlations with the scales assessing behavioral regulation: Set Shifting, Inhibition, Emotional Control, and Self-Monitoring. Hierarchical regression analyses revealed that these relationships remained significant after controlling for demographic variables (e.g., gender, body mass index, age, education level) and diagnoses of an eating disorder, obsessive-compulsive disorder, attention deficit/hyperactivity disorder, autism, and learning disability.

Conclusion: These findings suggest that, despite unique manifestations, orthorexia and anorexia may possess an overlapping neuropsychological profile marked by deficits in executive function, which may negatively impact daily life.
\end{abstract}

Level of evidence: Level V, descriptive cross-sectional study

Keywords: Orthorexia nervosa; Executive function; Behavioral control; Emotional control 


\section{Introduction}

Comprehensive literature reviews reveal that, compared to healthy controls, people with anorexia nervosa $(\mathrm{AN})$ and bulimia nervosa $(\mathrm{BN})$ demonstrate impairments in executive function $[1,2]$. These impairments include deficits in cognitive flexibility (i.e., the inability to adapt one's behaviors or thoughts in response to new events or information) and deficits in inhibitory control (i.e., the inability to suppress a behavior or thought). Moreover, these deficits seem to be especially significant in AN compared to $\mathrm{BN}$, especially after controlling for body mass index (BMI) and level of depression [3, 4]. Some researchers even theorize that this executive dysfunction is an endophenotype for $\mathrm{AN}$, a mediating factor that contributes to the development and maintenance of the disorder that involves rigid rule-bound behaviors and thought preoccupation $[5,6]$.

\section{Orthorexia vs. Anorexia}

Another eating disorder involving rule-bound behaviors and thought preoccupation is orthorexia nervosa $(\mathrm{ON})$, which is characterized by compulsive behaviors and obsessive thoughts about healthy eating and nutrition [7]. Common among multiple sets of proposed diagnostic criteria for $\mathrm{ON}$ are the following: (a) rigidly following a very restrictive diet that the individual believes to be as pure and healthy as possible; (b) violations of this diet causing emotional distress with feelings of extreme anxiety and shame; (c) physical impairments resulting from nutritional deficiencies associated with such a restrictive diet; and (d) psychosocial impairments impacting their relationships and their academic or vocational functioning [8-12].

Research investigating ON reveals that this condition shares certain characteristics with AN. Like AN, ON is associated with comparatively higher scores on measures of disordered eating that include items about dietary restriction and weight preoccupation [13-19]. 
Additionally, AN and $\mathrm{ON}$ are both associated with comparatively higher levels of anxiety, perfectionism, and the need to have complete control over their environment $[15,20]$.

Yet, ON differs from AN in other respects. From a theoretical perspective, whereas the disordered eating in AN is largely driven by a distorted body image, the disordered eating in ON is predominantly driven by the need to be as healthy and pure as possible $[7,10]$. In addition, AN and $\mathrm{ON}$ differ in relation to gender and $\mathrm{BMI}$ associations. Regarding $\mathrm{AN}$, a low $\mathrm{BMI}$ is a diagnostic criterion for AN [21], and women outnumber men in AN prevalence at an average ratio of 9:1 [22, 25]. In contrast, comprehensive literature reviews reveal that the majority of studies found $\mathrm{ON}$ to be unrelated to both gender and BMI [26, 27].

\section{Orthorexia and Executive Function}

The question of the current study concerns whether $\mathrm{ON}$ is associated with impairments in executive function, which would suggest that despite the unique manifestations identified above, $\mathrm{ON}$ and AN possess an overlapping neuropsychological profile. Regarding cognitive flexibility, the extreme rigidity of $\mathrm{ON}$ behaviors (e.g., consuming specific foods in specific quantities at specific times) and thoughts (e.g., steadfast belief that their dietary regime is superior to others) reflect an inflexible mindset. Regarding inhibitory control, numerous studies found that restrained eating, comparable to the very restrictive diet of those with $\mathrm{ON}$, is associated with deficits in inhibitory control [28-31].

The limited research investigating this question found that $\mathrm{ON}$ is unrelated to performance on traditional neuropsychological assessments of executive function. Namely, ON symptomatology was unrelated to performance on the Wisconsin Card Sorting Test and Trail Making Test that assess cognitive flexibility or set shifting [32, 33], and unrelated to performance on the Stroop Task, Go/No-Go Task, and Flanker Task that assess inhibitory 
control or response inhibition [32, 34]. These initial findings suggest that $\mathrm{ON}$ is not associated with executive dysfunction.

However, one of these three studies did find ON symptomatology to be significantly correlated with scores on the Behavior Rating Inventory of Executive Function-Adult version (BRIEF-A) [32]. The BRIEF-A [35] is a self-report survey in which participants are asked about problems with their functioning in real-life situations. It includes four scales assessing behavioral regulation and five scales assessing metacognition. Koven and Senbonmatsu [32] found that greater levels of ON symptomatology were associated with higher scores on all four behavioral regulation scales (i.e., Set Shifting, Inhibition, Emotional Control, Self-Monitoring) and on four of the five metacognition scales (i.e., Working Memory, Planning/Organization, Task Initiation, Task Monitoring). Subsequent regression analyses, controlling for disordered eating and obsessive-compulsive variables, revealed unique contributions from ON to four scales: Set Shifting, Emotional Control, Self-Monitoring, and Working Memory.

So, how can ON be related to executive dysfunction assessed with the self-report BRIEFA, but not to executive dysfunction assessed with the traditional performance-based tests? Although some studies have found significant correlations between scores on the BRIEF-A and on performance-based measures of executive function $[5,36,37]$, many studies found these relationships to be either minimal or nonexistent [38-45]. Whereas the performance-based assessments are objective measures that are presumably immune to social-desirability biases, many researchers argue that they are less ecologically valid than self-report tests [35, 46-48]. These researchers suggest this is because performance-based assessments measure executive function in very controlled, artificial environments that do not represent more complex, daily-life environments where behavior is impacted by a multitude of factors including emotional distress. Regarding additional validity of the BRIEF-A, researchers have found that people with AN 
scored higher than healthy controls on the behavioral regulation scales [49], and that disordered eating levels were positively correlated with scores on the behavioral regulation scales in a nonclinical sample [50].

\section{Purpose of the Current Study}

Using the BRIEF-A, Koven and Senbonmatsu [32] found that greater levels of ON symptomatology corresponded to greater deficits in executive function, with the strongest correlations for the behavioral regulation scales. However, this study included a relatively small sample of only 100 participants, and it used the ORTO-15 [51] that research shows is lacking in reliability and validity as a measure of $\mathrm{ON}[9,10,17,27,52]$. The current study recruited a larger sample of over 400 participants who completed the BRIEF-A along with a different measure of ON that has been established as reliable and valid, to further explore whether ON symptomatology is associated with deficits in executive function that may impact their daily lives.

\section{Method}

\section{Participants}

A convenience sample of participants was recruited from undergraduate courses (in psychology, nutrition, athletics, and exercise science) at a large, southern-region United States university. Additionally, participants were recruited through a targeted Instagram advertisement aimed at reaching audiences that participate in food health social media. Target terms included phrases such as "clean eating", "eat to live", and "paleo diet". The purpose of participant recruitment via health-related courses and targeted advertisement was to increase the likelihood of obtaining participants with ON symptomatology. Our sample included 405 participants, the majority of whom were White (53\%; 15\% Asian American or Pacific Islander; $13 \%$ Hispanic or Latinx; $11 \%$ Black; $7 \%$ biracial or multiracial; $1 \%$ Native American), identified as women (80\%; $15 \%$ male; $5 \%$ non-binary or gender fluid), and had some college without having completed a 
degree (31\%; 23\% Bachelor's degree; 17\% some high school, no diploma; 15\% high school diploma or GED; 6\% Associates degree; 5\% Master's degree; 2\% trade/technical/vocational training; $1 \%$ doctorate degree). Participant ages ranged from 17 years to 73 years $(M=24.16, S D$ $=9.24)$ and body mass index $(\mathrm{BMI})$ ranged from $14.56 \mathrm{~kg} / \mathrm{m}^{2}$ to $52.14 \mathrm{~kg} / \mathrm{m}^{2}(M=24.55, S D=$ 5.86).

\section{Procedure}

This study was approved by the Texas State University Institutional Review Board. For this study, participants provided informed consent and were then asked to complete a survey through the online platform Qualtrics. The survey included an initial demographics questionnaire, followed by a measure of $\mathrm{ON}$, and lastly a measure of executive function.

\section{Materials}

ON was assessed using the Orthorexia Nervosa Inventory (ONI) [17], which consists of 24 statements. Participants rate each statement on a 4-point Likert scale to indicate how applicable the statement is to their current eating behaviors. This inventory includes statements pertaining to obsessive behaviors and preoccupations with healthy eating (e.g., "I follow a health-food diet rigidly, only eating what my diet allows and not allowing myself any deviations from this diet"), psychosocial impairments (e.g., "As a result of the amount of time I devote to my healthy diet, I have spent less time than I used to with my family or friends") and physical impairments (e.g., "Even though I have eaten much healthier over time, my physical health has actually declined") relative to extreme ON behaviors, and emotional distress relative to deviation from dietary rules (e.g., "When I stray from my healthy diet, I can only think about what a failure I am"). Higher total scores are indicative of greater ON severity. For the current study, internal reliability was high with Cronbach's $\alpha=.93$, consistent with the initial validation study value of $.94[17]$ 
The BRIEF-A [35] was used to assess executive dysfunction in the everyday lives of participants. The BRIEF-A consists of 75 statements that participants rate as "never", "sometimes", or "often" occurring problematically within the last month. This inventory is comprised of nine subscales which are categorized into two composite subscales. The first composite subscale, Behavioral Regulation, includes eight Inhibition subscale statements (e.g., "I tap my fingers or bounce my legs"), six Set Shifting subscale statements (e.g., "I have trouble changing from one activity or task to another"), ten Emotional Control subscale statements (e.g., "I have angry outbursts"), and six Self-Monitoring subscale statements (e.g., "I talk at the wrong time"). The second composite subscale, Metacognition, includes eight Initiation subscale statements (e.g., "I have trouble getting ready for the day"), eight Working Memory subscale statements (e.g., "I forget what I am doing in the middle of things"), ten Planning/Organizing subscale statements (e.g., "I get overwhelmed by large tasks"), six Task Monitoring subscale statements (e.g., "I make careless errors when completing tasks"), and eight Organization subscale statements (e.g., "I have a messy closet"). Higher scores are indicative of greater executive dysfunction on all subscales. For the current study, internal consistency was moderate to high with Cronbach's $\alpha=.98$ for the BRIEF-A total score and Cronbach's $\alpha$ ranging from .79 to .92 for the subscales, consistent with the initial validation study values of .96 for the BRIEF-A total score and .73-.90 for the subscales [35].

\section{Statistical Analyses}

Data were analyzed using the SPSS Statistics 26 software. Pearson correlation analyses were first conducted with the scores on the ONI and each of the BRIEF-A subscales to assess whether ON symptomatology is related to deficits in executive function. Then, for each BRIEFA scale that was significantly correlated with the ONI score, hierarchical regression analyses were conducted to determine whether those relationships remained significant after controlling 
for key demographic variables that may be related to executive function. In each hierarchical regression analysis, the following demographic predictor variables were entered in the first step: gender, BMI, age, education level, eating disorder diagnosis, obsessive-compulsive disorder diagnosis, attention deficit/hyperactivity disorder diagnosis, autism diagnosis, and learning disability diagnosis. ONI score was entered in the second step, and the BRIEF-A subscale scores were the dependent variables for the analyses. For all tests, the standard alpha criterion of .05 was used to determine statistical significance. For significant correlations, an $r$ value of .1 was considered a weak relationship, .3 a moderate relationship, and .5 a strong relationship.

\section{Results}

Table 1 shows the preliminary findings on associations between $\mathrm{ON}$ and executive dysfunction. All relationships were statistically significant with higher scores on all BRIEF-A subscales (i.e., greater executive dysfunction) associated with higher ONI scores (i.e., greater ON severity). The associations with a moderate magnitude were between ONI scores and scores on the BRIEF-A Inhibition and Emotional Control subscales, both of which are Behavioral Regulation components of the inventory; the remaining associations were weak in magnitude.

Table 2 presents the combined findings from the nine hierarchical regression analyses. For each analysis, the Model 1 results demonstrated that the BRIEF-A subscale score was significantly predicted by the demographic variables entered in the first step of the analysis: gender, BMI, age, highest level of education, and diagnoses of any eating disorder, obsessivecompulsive disorder, attention deficit hyperactivity disorder, autism, and learning disability. Of primary interest, however, are the Model 2 results. After accounting for variability due to these demographics, the ONI score accounted for a significant amount of additional variation in scores for eight of the BRIEF-A subscales: Set Shifting, Inhibition, Emotional Control, SelfMonitoring, Working Memory, Task Initiation, Task Monitoring, and Planning/Organizing. 
Table 1

Correlations with ONI Scores

\begin{tabular}{ll}
\hline BRIEF-A Scale & $r$ \\
\hline Behavioral Regulation & \\
Set Shifting & $.25^{* * *}$ \\
Inhibition & $.30^{* * *}$ \\
Emotional Control & $.34^{* * *}$ \\
Self-Monitoring & $.28^{* * *}$ \\
\hline Metacognition & \\
Working Memory & $.24^{* * *}$ \\
Task Initiation & $.20^{* * *}$ \\
Task Monitoring & $.21^{* * *}$ \\
Planning/Organizing & $.25^{* * *}$ \\
Organization of Materials & $.12^{*}$
\end{tabular}

Note. ONI = Orthorexia Nervosa Inventory [17]; BRIEF-A = Behavior Rating Inventory of Executive Function-Adult [35].

${ }^{*} p<.05 .{ }^{* * *} p<.01$.

Table 2

Hierarchical Regression Analyses

\begin{tabular}{|c|c|c|c|c|c|}
\hline \multirow[b]{2}{*}{ BRIEF-A Scale } & \multicolumn{2}{|c|}{ Model 1 with Demographics ${ }^{a}$} & \multicolumn{3}{|c|}{ Model 2 with ONI Added ${ }^{\mathrm{b}}$} \\
\hline & $R^{2}$ & $F$ & $\Delta R^{2}$ & $F$ change & $\beta$ for $\mathrm{ONI}$ \\
\hline \multicolumn{6}{|l|}{ Behavioral Regulation } \\
\hline Set Shifting & .13 & $6.23^{* * *}$ & .03 & $14.05^{* * *}$ & $.19^{* * * *}$ \\
\hline Inhibition & .23 & $12.70^{* * *}$ & .04 & $20.75^{* * *}$ & $.22^{* * *}$ \\
\hline Emotional Control & .16 & $7.95^{* * *}$ & .06 & $31.45^{* * *}$ & $.28^{* * *}$ \\
\hline Self-Monitoring & .13 & $6.66^{* * *}$ & .04 & $19.93^{* * *}$ & $.23^{* * *}$ \\
\hline \multicolumn{6}{|l|}{ Metacognition } \\
\hline Working Memory & .24 & $13.28^{* * *}$ & .02 & $10.83^{* *}$ & $.16^{* *}$ \\
\hline Task Initiation & .20 & $10.59^{* * *}$ & .01 & $5.60^{*}$ & $.12^{*}$ \\
\hline Task Monitoring & .18 & $9.24^{* * * *}$ & .02 & $8.27^{* *}$ & $.15^{* *}$ \\
\hline Planning/Organizing & .18 & $9.74^{* * *}$ & .03 & $12.18^{* * *}$ & $.18^{* * *}$ \\
\hline Organization of Materials & .17 & $8.91^{* * *}$ & .01 & 2.91 & .09 \\
\hline
\end{tabular}

Note. ONI = Orthorexia Nervosa Inventory [17]; BRIEF-A = Behavior Rating Inventory of Executive Function-Adult [35].

aPredictors for Model 1 included the following demographic variables: gender, BMI, age, education level, eating disorder diagnosis, obsessive-compulsive disorder diagnosis, attention deficit/hyperactivity disorder diagnosis, autism diagnosis, and learning disability diagnosis.

${ }^{\text {b} P r e d i c t o r s ~ f o r ~ M o d e l ~} 2$ included the demographic variables identified above, along with the addition of the ONI score.

${ }^{*} p<.05 .{ }^{* *} p<.01 .{ }^{* * *} p<.01$. 
ONI scores were most strongly predictive of executive dysfunction in the Behavioral Regulation component of the inventory, specifically in the Inhibition, Emotional Control, and SelfMonitoring subscales.

\section{Discussion}

\section{Key Findings and Implications}

The current study sought to replicate the work of Koven and Senbonmatsu [32] but using a larger sample size and a more reliable and valid measure of ON. In their study with 100 participants and using the ORTO-15 [51], Koven and Senbonmatsu found that greater levels of ON symptomatology were significantly associated with higher scores on eight of the nine subscales from the BRIEF-A [35], with the greatest correlations being with the four Behavioral Regulation subscales (i.e., Set Shifting, Inhibition, Emotional Control, Self-Monitoring). In comparison, we found that in the current study with 405 participants and using the ONI [17], ON symptomatology significantly correlated with all BRIEF-A subscales, with the greatest correlations also being with the four Behavioral Regulation subscales. Further, after controlling for demographics and comorbid diagnoses, $\mathrm{ON}$ severity remained a predictor of executive dysfunction, with the greatest associations once again being with the four Behavioral Regulation subscales, most notably the Inhibition, Emotional Control, and Self-Monitoring subscales.

Our findings show that $\mathrm{ON}$ symptomatology is associated with executive dysfunction in the completion of daily tasks, suggesting that the negative impact of ON on quality of life may correspond to trends in executive dysfunction. Moreover, whereas people with ON present symptoms differently from those with AN, our findings demonstrate that there are shared trends in impairments involving executive function. Both disorders involve an inflexible mindset with rigid rule-bound behaviors and thought preoccupation. Some researchers even theorize that executive dysfunction is an endophenotype for $\mathrm{AN}$, a mediating factor that contributes to the 
development and maintenance of the disorder [5, 6]. Regardless of that theory, however, AN and ON seem to possess an overlapping neuropsychological profile characterized by impaired executive functioning, as well as similarly higher levels in such traits as anxiety, perfectionism, and need for control over their environment $[15,20]$.

\section{Limitations and Future Directions}

Although we recruited a relatively large sample and assessed ON with a reliable and valid measure based on the proposed diagnostic criteria for this disorder, limitations for the current study should be considered. First, most of the participants were female (80\%), White (53\%), young adults $(M=24$ years $)$, which may affect generalizability of the results. Second, this study utilized self-report measures that may be subject to self-report bias. Third, the participants predominantly comprised a non-clinical sample of individuals without an ON diagnosis. However, $\mathrm{ON}$ is not currently recognized as a psychiatric disorder in the Diagnostic and Statistical Manual of Mental Disorders, Fifth Edition (DSM-5) [21], such that clinicians do not have a singular set of agreed-upon criteria from which they may base a formal diagnosis.

Extending from these limitations, to increase the generalizability of the findings, future research should utilize a sample that is more demographically diverse and includes patients with an ON diagnosis. Moreover, future studies should more closely examine potential differences in executive dysfunction between $\mathrm{ON}$ and disorders with similar neuroprofiles, namely $\mathrm{AN}$ and obsessive-compulsive disorder, using the same measures and controlling for important demographics (e.g., gender, age) and psychological variables (e.g., anxiety, depression). Additionally, longitudinal studies would be invaluable in assessing whether executive dysfunction serves as a mediating variable in the development of these disorders, as researchers have suggested may be the case for ON [5, 6]. Finally, research investigating the perceived 
impact of executive dysfunction in the daily life of ON individuals may provide insights into ON's impact on quality of life.

\section{What is already known on this subject?}

Although three studies found that orthorexia is unrelated to performance on traditional neuropsychological assessments of executive function, other researchers argue that such assessments lack ecological validity due to the artificial tasks and environments not being representative of daily life.

\section{What does this study add?}

This study found that orthorexia is associated with executive dysfunction, assessed with the BRIEF-A self-report measure that addresses problems functioning in real-life situations.

Comparable to anorexia, orthorexia was most strongly associated with impairments in behavioral regulation, including cognitive flexibility, inhibitory control, and emotional control.

\section{Compliance with Ethical Standards}

Conflict of interest: The authors declare no conflict of interest.

Ethical approval: All procedures performed in this study involving human participants were in accordance with the ethical standards of the Texas State University Institutional Review Board and with the 1964 Helsinki declaration and its later amendments or comparable ethical standards. Informed consent: Informed consent was obtained from all individual participants included in the study. 


\section{References}

1. Jáuregui-Lobera I (2013) Neuropsychology of eating disorders: 1995-2012. Neuropsychiatr Dis Treat 9:415-430. https://doi.org/10.2147/NDT.S427

2. Wu M, Brockmeyer T, Hartmann M, Skunde M, Herzog W, Friederich HC (2014) Setshifting ability across the spectrum of eating disorders and in overweight and obesity: a systematic review and meta-analysis. Psychol Med 44:3365-3385. https://doi.org/10.1017/S0033291714000294

3. Segura-Serralta M, Ciscar S, Blasco L, Oltra-Cucarella J, Roncero M, Espert R, et al (2020) Contribution of executive functions to eating behaviours in obesity and eating disorders. Behav Cogn Psychother 48:725-733. https://doi.org/10.1017/S1352465820000260

4. Weider S, Indredavik MS, Lydersen S, Hestad K (2015) Neuropsychological function in patients with anorexia nervosa or bulimia nervosa. Int J Eat Disord 48:397-405. https://doi.org/10.1002/eat.22283

5. Herbrich LR, Kappel V, Winter SM, van Noort BM (2019) Executive functioning in adolescent anorexia nervosa: neuropsychology versus self- and parental-report. Child Neuropsychol 25:816-835. https://doi.org/10.1080/09297049.2018.1536200

6. Talbot A, Hay P, Buckett G, Touyz S (2015) Cognitive deficits as an endophenotype for anorexia nervosa: an accepted fact or a need for re-examination? Int J Eat Disord 48:15-25. https://doi.org/10.1002/eat.22332

7. Bratman S, Knight D (2000) Health food junkies: overcoming the obsession with healthful eating. Broadway Books, New York

8. Barthels F, Meyer F, Pietrowsky R (2015) Duesseldorf orthorexia scale-construction and evaluation of a questionnaire measuring orthorexic eating behavior. Z Klin Psychol Psychother 44:97-105. https://doi.org/10.1026/1616-3443/a000310 
9. Cena H, Barthels F, Cuzzolaro M, Bratman S, Brytek-Matera A, Dunn T, et al (2019) Definition and diagnostic criteria for orthorexia nervosa: a narrative review of the literature. Eat Weight Disord 24:209-246. https://doi.org/10.1007/s40519-018-0606-y

10. Dunn TM, Bratman S (2016) On orthorexia nervosa: a review of the literature and proposed diagnostic criteria. Eat Behav 21:11-17. https://doi.org/10.1016/j.eatbeh.2015.12.006

11. Moroze RM, Dunn TM, Holland JC, Yager J, Weintraub P (2015) Microthinking about micronutrients: a case of transition from obsessions about health eating to near-fatal “orthorexia nervosa” and proposed diagnostic criteria. Psychosomatics 56:397-403. https://doi.org/10.1016/j.psym.2014.03.003

12. Setnick J (2013) The eating disorders clinical pocket guide: quick reference for healthcare providers (2nd edn). Understanding Nutrition, Dallas, TX

13. Barthels F, Meyer F, Pietrowsky R (2018) Orthorexic and restrained eating behaviour in vegans, vegetarians, and individuals on a diet. Eat Weight Disord 23:159-166. https://doi.org/10.1007/s40519-018-0479-0

14. Brytek-Matera A, Krupa M, Poggiogalle E, Donini LM (2014) Adaptation of the ORTHO-15 test to Polish women and men. Eat Weight Disord 19:69-76. https://doi.org/10.1007/s40519014-0100-0

15. Bundros J, Clifford D, Silliman K, Morris MN (2016) Prevalence of orthorexia nervosa among college students based on Bratman's test and associated tendencies. Appetite 101:8694. https://doi.org/10.1016/j.appet.2016.02.144

16. Hayes O, Wu MS, De Nadai AS, Storch EA (2017) Orthorexia nervosa: an examination of the prevalence, correlates, and associated impairment in a university sample. J Cogn Psychother 31:124-135. https://doi.org/10.1891/0889-8391.31.2.124 
17. Oberle CD, De Nadai AS, Madrid AL (2021) Orthorexia Nervosa Inventory (ONI): development and validation of a new measure of orthorexic symptomatology. Eat Weight Disord 26:609-622. https://doi.org/10.1007/s40519-020-00896-6

18. Segura-Garcia C, Papaianni MC, Caglioti F, Procopio L, Nistico CG, Bombardiere L, et al (2012) Orthorexia nervosa: a frequent eating disorder behavior in athletes. Eat Weight Disord 17:223-233. https://doi.org/10.3275/8272

19. Segura-Garcia C, Ramacciotti C, Rania M, Aloi M, Caroleo M, Bruni A, et al (2015) The prevalence of orthorexia nervosa among eating disorder patients after treatment. Eat Weight Disord 20:161-166. https://doi.org/10.1007/s40519-014-0171-y

20. Koven NS, Abry WA (2015) The clinical basis of orthorexia nervosa: emerging perspectives. Neuropsychiatry Dis Treat 11:385-394. http://doi.org/10.2147/NDT.S6166

21. American Psychiatric Association (2013) Diagnostic and statistical manual of mental disorders (5th edn). Author, Washington, DC

22. Fisher MM, Rosen DS, Ornstein RM, Mammel KA, Katzman DK, Rome ES, et al (2014) Characteristics of avoidant/restrictive food intake disorder in children and adolescents: a "new disorder" in DSM-5. J Adolesc Health 55:49-52. https://doi.org/10.1016/j.jadohealth.2013.11.013

23. Forman SF, McKenzie N, Hehn R, Monge MC, Kapphahn CJ, Mammel KA, et al (2014) Predictors of outcome at 1 year in adolescents with DSM-5 restrictive eating disorders: report of the National Eating Disorders Quality Improvement Collaborative. J Adolesc Health 55:750-756. https://doi.org/10.1016/j.jadohealth.2014.06.014

24. Nicely TA, Lane-Loney S, Masciulli E, Hollenbeak CS, Ornstein RM (2014) Prevalence and characteristics of avoidant/restrictive food intake disorder in a cohort of young patients in 
day treatment for eating disorders. J Eat Disord 2:21. https://doi.org/10.1186/s40337-0140021-3

25. Norris ML, Robinson A, Obeid N, Harrison M, Spettigue W, Henderson K (2014) Exploring avoidant/restrictive food intake disorder in eating disordered patients: a descriptive study. Int J Eat Disord 47:495-499. https://doi.org/10.1002/eat.22217

26. McComb SE, Mills JS (2019) Orthorexia nervosa: a review of psychosocial risk factors. Appetite 140:50-75. https://doi.org/10.1016/j.appet.2019.05.005

27. Oberle CD, Samaghabadi RO, Hughes EM (2017) Orthorexia nervosa: assessment and correlates with gender, BMI, and personality. Appetite 108:303-310. https://doi.org/10.1016/j.appet.2016.10.021

28. Brooks S, Prince A, Stahl D, Campbell IC, Treasure J (2011) A systemic review and metaanalysis of cognitive bias to food stimuli in people with disordered eating behavior. Clin Psychol Rev 31:37-51. http://doi.org/10.1016/j.cpr.2010.09.006

29. Dobson KS, Dozois DJA (2004) Attentional biases in eating disorders: a meta-analytic review of Stroop performance. Clin Psychol Rev 23:1001-1022. http://doi.org/10.1016/j.cpr.2003.09.004

30. Houben K, Nederkoorn C, Jansen A (2012) Too tempting to resist? Past success at weight control rather than dietary restraint determines exposure-induced disinhibited eating. Appetite 59:550-555. https://doi.org/10.1016/j.appet.2012.07.004

31. Merson B, Pezdek P (2016) Response inhibition and interference suppression in restraining eating. J Appl Res Mem Cogn 5:345-351. http://doi.org/10.1016/j.jarmac.2016.07.004

32. Koven NS, Senbonmatsu R (2013) A neuropsychological evaluation of orthorexia nervosa. Open J Psychiatry 3:214-222. http://doi.org/10.4236/ojpsych.2013.32019 
33. Hayatbini N, Oberle CD (2019) Are orthorexia nervosa symptoms associated with cognitive inflexibility? Psychiatry Res 271:464-468. http://doi.org/10.1016/j.psychres.2018.12.017

34. Hayatbini N, Oberle CD, Ali MN (2021) Are orthorexia nervosa symptoms associated with deficits in inhibitory control? Eat Weight Disord 26:1553-1557. https://doi.org/10.1007/s40519-020-00979-4

35. Roth RM, Isquith PK, Gioia GA (2005) BRIEF-A: Behavior Rating Inventory of Executive Function-Adult Version. Psychological Assessment Resources

36. Baker KS, Gibson SJ, Georgiou KN, Giummarra MJ (2018) Relationship between selfreported cognitive difficulties, objective neuropsychological test performance and psychological distress in chronic pain. Eur J Pain 22:601-613. https://doi.org/10.1002/ejp.1151

37. García-Molina A, Tormos JM, Bernabeu M, Junqué C, Roig-Rovira T (2012) Do traditional executive measures tell us anything about daily-life functioning after traumatic brain injury in Spanish-speaking individuals? Brain Inj 26:864-874.

https://doi.org/10.3109/02699052.2012.655362

38. Hauger LE, Westlye LT, Bjørnebekk A (2020) Anabolic androgenic steroid dependence is associated with executive dysfunction. Drug Alcohol Depend 208:107874. https://doi.org/10.1016/j.drugalcdep.2020.107874

39. Løvstad M, Funderud I, Endestad T, Due-Tønnessen P, Meling TR, Lindgren M, et al (2012) Executive functions after orbital or lateral prefrontal lesions: neuropsychological profiles and self-reported executive functions in everyday living. Brain Inj 26:1586-1598. https://doi.org/10.3109/02699052.2012.698787

40. Løvstad M, Sigurdardottir S, Andersson S, Grane VA, Moberget T, Stubberud J, Solbakk AK (2016) Behavior rating inventory of executive function adult version in patients with 
neurological and neuropsychiatric conditions: symptom levels and relationship to emotional distress. J Int Neuropsychol Soc 22:682-694. https://doi.org/10.1017/S135561771600031X

41. Meltzer EP, Kapoor A, Fogel J, Elbulok-Charcape MM, Roth RM, Katz MJ, et al (2017) Association of psychological, cognitive, and functional variables with self-reported executive functioning in a sample of nondemented community-dwelling older adults. Appl Neuropsychol Adult 24:364-375. https://doi.org/10.1080/23279095.2016.1185428

42. Rabin LA, Roth RM, Isquith PK, Wishart HA, Nutter-Upham KE, Pare N, et al (2006) Selfand informant reports of executive function on the BRIEF- A in MCI and older adults with cognitive complaints. Arch Clin Neuropsychol 21:721-732. https://doi.org/10.1016/j.acn.2006.08.004

43. Rodrigue C, Ouellette A, Lemieux S, Tchernof A, Biertho L, Bégin C (2018) Executive functioning and psychological symptoms in food addiction: a study among individuals with severe obesity. Eat Weight Disord 23:469-478. https://doi.org/10.1007/s40519-018-0530-1

44. Rouel M, Raman J, Hay P, Smith E (2016) Validation of the Behaviour Rating Inventory of Executive Function-Adult Version (BRIEF-A) in the obese with and without binge eating disorder. Eat Behav 23:58-65. https://doi.org/10.1016/j.eatbeh.2016.07.010

45. Shwartz SK, Roper BL, Arentsen TJ, Crouse EM, Adler MC (2020) The Behavior Rating Inventory of Executive Function ${ }^{\circledR}$-Adult Version is related to emotional distress, not executive dysfunction, in a veteran sample. Arch Clin Neuropsychol 35:701-716. https://doi.org/10.1093/arclin/acaa024

46. Blijd-Hoogewys EMA, Bezemer ML, van Geert PLC (2014) Executive functioning in children with ASD: an analysis of the BRIEF. J Autism Dev Disord 44:3089-3100. https://doi.org/10.1007/s10803-014-2176-9 
47. Gioia GA, Isquith PK (2004) Ecological assessment of executive function in traumatic brain injury. Dev Neuropsychol 25:135-158. https://doi.org/10.1207/s15326942dn2501\&2_8

48. Isquith PK, Roth RM, Gioia G (2013) Contribution of rating scales to the assessment of executive functions. Appl Neuropsychol Child 2:125-132. https://doi.org/10.1080/21622965.2013.748389

49. Herbrich L, Kappel V, van Noort BM, Winter S (2018) Differences in set-shifting and central coherence across anorexia nervosa subtypes in children and adolescents. Eur Eat Disord Rev 26:499-507. https://doi.org/10.1002/erv.2605

50. Ciszewski S, Flood KE, Proctor CJ, Best LA (2020) Exploring the relationship between disordered eating and executive function in a non-clinical sample. Percept Mot Skills 127:1033-1050. https://doi.org/10.1177/0031512520937569

51. Donini LM, Marsili D, Graziani MP, Imbriale M, Cannella C (2005) Orthorexia nervosa: validation of a diagnosis questionnaire. Eat Weight Disord 10:28-32. https://doi.org/10.1007/BF03327537

52. Missbach B, Dunn TM, König JS (2017) We need new tools to assess orthorexia nervosa: a commentary on 'Prevalence of orthorexia nervosa among college students based on Bratman's test and associated tendencies'. Appetite 108:521-524. https://doi.org/10.1016/j.appet.2016.07.010 